\title{
Redescription of a weevil Paramecops sinaitus (Coleoptera: Curculionidae: Molytinae) from the Sinai and an ecological study of its interaction with the Sinai milkweed Asclepias sinaica (Gentianales: Asclepiadaceae)
}

\author{
Tim NEWBOLD ${ }^{1}$, Massimo MEREGALli ${ }^{2}$, Enzo COLONNELLI ${ }^{3}$, Maxwell BARCLAY ${ }^{4}$, Shereen ELBANNA 5 , \\ NANCy ABU FANDUD ${ }^{5}$, Frank FLEGG ${ }^{1}$, Rasha FOUAD ${ }^{5}$, Francis GILBERT ${ }^{1}$, Vanessa HALL ${ }^{1}$, Claire \\ HANCOCK $^{1}$, MONA ISMAIL ${ }^{5}$, SAMr OSAMY ${ }^{5}$, ISRA'A SABER ${ }^{5}$, FAYEZ SEMIDA $^{5}$ and SAMY ZALAT ${ }^{5}$ \\ ${ }^{1}$ School of Biology, University of Nottingham, Nottingham, UK; e-mail: timnewbold22@yahoo.co.uk \\ ${ }^{2}$ Department of Animal and Human Biology, University of Torino, Torino, Italy \\ ${ }^{3}$ Via delle Giunchiglie 56, Roma, Italy \\ ${ }^{4}$ Department of Entomology, The Natural History Museum, London, UK \\ ${ }^{5}$ Department of Zoology, Suez Canal University, Ismailia, Egypt
}

Key words. Curculionidae, Asclepias sinaica, chemical defence, coevolution, herbivory, new combination, new synonymies, Paramecops sinaitus, plant-insect interactions, redescription, secondary metabolites, taxonomy

\begin{abstract}
We collected specimens of Paramecops sinaitus (Pic, 1930) (Curculionidae: Molytinae) from south Sinai in Egypt, which enabled us to make the first complete description of this species. We also include some taxonomic remarks on the genus. Paramecops solenostemmatis (Peyerimhoff, 1930) is a synonym of Paramecops sinaitus. We propose the new combination Paramecops sogdianus (Nasreddinov, 1978), based on Perihylobius sogdianus Nasreddinov, 1978, which would make Perihylobius and Paramecops synonymous. Like other Paramecops species, P. sinaitus appears to share a close interaction with Asclepiads, in this case the Sinai milkweed Asclepias sinaica (Boiss.) Muschl., 1912 (Asclepiadaceae). We investigated the oviposition behaviour of female weevils to test whether it is linked to larval performance, as predicted by coevolutionary theory. We found that female oviposition preference was positively related to plant size and to the volume of the seed follicles in which the eggs were laid. The survival of eggs was negatively related to plant size, perhaps due to plant differences in the production of defensive cardenolides. Larval survival was not related to plant size but increased with follicle volume, probably as a result of competition for food. Paramecops is relatively sedentary and nocturnal in its behaviour. Night-time observations of behaviour showed that weevils were more active at lower temperatures.
\end{abstract}

\section{INTRODUCTION}

Most phytophagous insects exploit a narrow range of host plants, despite the apparent nutritional advantages of a broader diet (Futuyma \& Gould, 1979). A number of explanations have been proposed for the evolution of host specialization including availability of hosts, avoidance of natural enemies (predators and parasites), increased ability to find mates and possession of mechanisms for attachment to particular host species (Bernays \& Graham, 1988). Host range may also be determined by the ability to overcome plant defences. These defences generally fall into one of two categories. The first are physical mechanisms, such as spines, hairs or smooth cuticles (Sabelis et al., 1998). The second group is the chemical defences; examples include the alkaloids, flavonoids, glucosinolates and terpenoids. These toxic chemicals, so-called secondary metabolites, are produced as by-products of major metabolic pathways, although it is now generally considered that they evolved specifically as a defence against herbivory (Fraenkel, 1959).

Herbivores have a number of ways of avoiding the negative fitness consequences of plant defences. Those with a broad host range (generalists) feed on plant species that have not evolved elaborate protection measures. Specialists on the other hand have developed ways to over- come the defences, enabling them to exploit food sources for which there is less competition. The appearance of secondary metabolites in particular, has provoked a wide range of counter-defences in herbivorous insects. Behavioural responses range from passively avoiding tissues with a high concentration of chemicals, to actively preventing the chemicals from reaching the desired food parts. A good example of such a response is seen in beetles of the genus Blepharida Dejean (1836) (Chrysomelidae). Their Burseraceae hosts have networks of canals containing resins under high pressure. When the plant is damaged, these resins squirt out soaking any herbivores in toxic terpenes. Several Blepharida species circumvent this defence by puncturing the canals before feeding (Becerra et al., 2001).

Many insect species have evolved metabolic resistance to the secondary chemicals of their hosts. For example, some members of the Burseraceae do not have high pressure canals; instead they produce a highly toxic cocktail of terpenes. Blepharida species which feed on these plants are able to metabolise these chemicals (Becerra et al., 2001). The mixed function oxidase (cytochrome P450) enzymes play an important role, both in the production of secondary metabolites by plants and in their metabolism by herbivores (Chown \& Nicholson, 2004). 
It is thought that many insect-plant interactions are examples of coevolution, with the emergence of plant defences causing the evolution of insect counter-defences, leading to better plant defences; and so on. Coevolutionary explanations for insect-plant interactions require that the interacting species exert reciprocal fitness effects on each other. Agrawal \& Van Zandt (2003) demonstrated this for the interaction between Rhyssomatus lineaticollis (Say, 1824) weevils and the common milkweed Asclepias syriaca Linnaeus. It has been suggested that the enormous diversity of insects and plants seen today may be the result of coevolutionary processes. Ehrlich \& Raven's (1964) escape-radiate hypothesis proposes that the evolution of a novel defence in a plant causes it to enter a new, herbivore-free adaptive zone in which it radiates. When an insect evolves a mechanism to overcome this defence, it also enters a new adaptive zone, free from competition, where it radiates onto the new plant species. Ehrlich \& Raven (1964) support this hypothesis with the observation that groups of closely-related insect species often feed on related groups of plants. Phylogenetic studies have since shown that radiation in insect groups often corresponds with radiation in their host plant families, lending further support to the model (Farrell \& Mitter, 1990).

\section{STUDY ORGANISMS}

The Asclepiadaceae has more than 2900 species, mainly African: the genus Asclepias Linnaeus has 100 species, mostly from the New World (Mabberley, 1997). Asclepias sinaica is not quite endemic to the Sinai, being found also in Palestine and widespread in Saudi Arabia (Collenette, 1985; Boulos, 2000). In common with other milkweeds, it has a system of latex canals that probably evolved to reduce herbivory. The non-articulated sealed canals contain latex under pressure, and any damage to the plant causes the latex to seep out and harden on contact with the air, trapping any insects that may have caused the damage (Farrell et al., 1991; Zalucki et al., 2001). The latex also contains cardenolides, a group of secondary metabolites which are toxic to most animals through disruption of the sodium-potassium channels in cell membranes, amyrin (a precursor of rubber), and other noxious chemicals (Malcolm, 1991; Farrell et al., 1991). The cardenolides usually occur as cardiac glycosides, and in $A$. sinaica are known to consist mainly of calotropin and its derivatives (El-Askary et al., 1993, 1995a,b; Abdel-Azim, 1998), although other components with interesting toxic properties are also present (El-Banna et al., 2003). In other milkweeds, the latex contains up to 50 times the concentration of cardenolides present in the rest of the leaf (Zalucki et al., 2001).

The fruit (a follicle) consists of a double-walled pericarp containing the seeds, each of which has a silky parachute for dispersal. When the follicle is mature, it dries and splits along predetermined sutures, releasing the wind-borne seeds. Follicles are extraordinarily reactive in exuding latex under even the slightest damage (including, for example, aphid stylet insertions, and merely brushing the follicular hairs). There are two crops of flowers per plant each year, usually in May and August to September.

From our own observations in Sinai, the weevil Paramecops sinaitus shows a close association with Asclepias sinaica. Interestingly, another member of the Molytinae, Rhyssomatus lineaticollis, which is found in the New World, shows a similar association with Asclepias syriaca (Agrawal \& Van Zandt, 2003). Paramecops sinaitus occurs frequently in the wadis around St Katherine in the St Katherine Protectorate, although only scattered individuals can normally be seen on the plants because during the day weevils roost in groups of up to a dozen or more in the leaf litter at the base of the plant. There appear to be two generations per year, in spring and in late-summer (August to September), matching the availability of seeds. The pupal stage lasts 13-14 days in July, but we do not know yet how long the larval stages take, nor details of how overwintering occurs.

Weevils feed on milkweed leaves in a very distinctive way, first puncturing the latex canal of the midrib, then eating the leaf distal to the wound. This is a form of "latex-canal sabotage behaviour", practised by many other milkweed herbivores (Zalucki et al., 2001). It leaves a characteristic crescent-shaped hole in one half of leaves that have been eaten. Unlike the monarch butterfly Danaus plexippus Linnaeus (1758) and the milkweed bug Spilostethus pandurus (Scopoli, 1763), both of which also feed on A. sinaica, $P$. sinaitus is not obviously aposematically coloured. In common with other Paramecops species it possesses a thick pruinose coating, which may instead make it cryptic, although an interesting possibility is that like scorpions this coating may be aposematic at night in ultra-violet light.

Female weevils oviposit by making a hole in the outer layer of the pericarp and laying a single, very large egg into the space below. Latex from the damaged pericarp forms a hard plug over the entrance to the hole, sealing the egg inside and protecting it as it develops. The larva hatches into the space between pericarp layers, sometimes wandering about before making a hole through the inner layer of the pericarp to enter the follicle. A single larva eats all of the seeds in order to reach maturity, and there is usually only a single survivor (but see Results). After passing through an unknown number of instars the larvae pupate inside a "cocoon" made from the silk threads of the seed parachutes, which effectively plugs the exit hole apparently bitten in advance by the mature larva. This plug protects the weevil from attack by parasitoids, of which there is at least one, not as yet reared and identified. Since the follicle splits open anyway, it is not clear why an exit hole is necessary for eclosion; perhaps the timing of eclosion requires an earlier release from the follicle than would happen naturally.

In this study, we investigate ecological aspects of the interaction between Paramecops sinaitus (Pic, 1930) (Curculionidae: Molytinae) and its host-plant, the Sinai milkweed Asclepias sinaica (Boiss.) Muschl., 1912 (Asclepiadaceae; following Boulos, 2000). If these species are coevolving, then they should exert reciprocal 
effects on each others' fitness. Individual differences in plant chemistry may therefore affect female oviposition choice and larval development. Measurement of individual differences in cardenolide levels is in progress and will be reported in due course, but here we consider a possible proxy, namely plant size. If the production of toxic cardenolides allows milkweed plants to grow to a larger size, then we would predict a negative relationship between plant size and larval survival. On the other hand if plants divert resources away from growth in order to produce cardenolides, we would expect a positive association. Follicle volume may also influence larval survival, through competition for food. We predict that larger follicles will contain more food, and therefore that a greater proportion of larvae will survive in these follicles.

\section{MATERIAL AND METHODS}

\section{Taxonomy}

This study is based on the specimens collected in Sinai by the authors, and on specimens of Paramecops housed in the Naturhistorisches Museum, Basel, Switzerland, the British Museum (Natural History), London, England, the Muséum National d'Histoire Naturelle, Paris, France, the Zoological Institute of the Russian Academy of Science, St. Petersburg, Russia, and the Meregalli Collection, Torino, Italy. Several specimens were dissected; female genitalia were embedded in Solacryl (Medika, Prague, Czech Republic) and male genitalia were mounted dry. Genitalia preparations are pinned below the specimen from which they were dissected. Drawings were made using a Wild M5A stereomicroscope and camera lucida; photographs were taken with a Nikon Coolpix 4500 camera, on the same stereomicroscope, and were elaborated with Photoshop 7.0 (Adobe Systems Incorporated) and Combine Z5 (available from: http://www.hadleyweb.pwp.blueyonder.co.uk/index.htm).

\section{Plant-insect interactions}

A study of the ecology of the Paramecops-Asclepias interaction was carried out in August and September, 2003 and 2004, in Wadi Arbaein $\left(28.6^{\circ} \mathrm{N}, 33.9^{\circ} \mathrm{E}\right)$ in the St. Katherine's Protectorate of south Sinai in Egypt. We divided the study site into five $100 \mathrm{~m}$ transects, at least $200 \mathrm{~m}$ apart, stretching the entire length of the wadi. Every plant $(\mathrm{N}=153)$ within the five transects was labelled with a unique number and given a 2-figure grid reference to identify its location.

For each plant, we made a survey of the insect species present: ants (Lepisiota spp.) were recorded as either present or absent; aphids (Aphis nerii Boyer de Fonscolombe) as the numbers of large (occupying $>7 \mathrm{~cm}$ of the stem), medium $(3-7 \mathrm{~cm})$ or small $(<3 \mathrm{~cm})$ colonies; and milkweed bugs (Spilostethus pandurus) and weevils as the total number of individuals. We also noted a number of plant characteristics, namely its size (measured as the number of stems from the current growing season), the number of live flower clusters and the number of leaves eaten by weevils, from a sample of fifty. The number of follicles on each plant was counted, categorised into those on old stems (presumed to be from the previous year, although they may have developed during the spring) and those on new stems (this summer's crop). Follicles on new stems were further classified as either open (i.e. dehisced) or closed (still undehisced). Preliminary observation indicated that follicles could have two types of hole in their pericarp; large weevil exit holes and small circular holes, approximately $5 \mathrm{~mm}$ in diameter. It is uncertain what caused the small holes but may have been a parasitoid wasp. We recorded the number of new follicles of each category (open and closed) with weevil holes and the number with small holes. Old follicles were simply classified as infested, if they had a hole of either sort, or uninfested.

For a more detailed analysis of individual follicles, we selected 12 plants which had a large number of follicles. We measured the length and width (at the widest point) of all follicles from these plants. For each follicle, we recorded the number of weevil exit holes and whether it was open or closed. Follicles were then examined under a light microscope and the number of latex plugs counted. Each plug was lifted with a pin and the presence of an oviposition hole noted; the location of each hole was classified as tip, middle or base (Fig. 3). The follicle was then carefully opened with a scalpel to determine whether any frass, "cocoons" or larvae were present. We used frass as an indicator of larval feeding in the follicle. We then removed all debris from the inside of the follicle and counted the number of holes on the inner surface. For follicles with no evidence of weevil attack, we also recorded the number of seeds.

\section{Weevil movement}

To study the movements of weevils between bushes, we marked 58 individuals by removing the pruinose coating from the elytra and applying spots of coloured paint. The weevils were then released onto bushes, in two separate study areas. We numbered every plant in these areas and recorded a number of characteristics of each, namely height (from the ground to the tip of the tallest stem), length (longest horizontal dimension), width (shortest horizontal dimension), number of old follicles, number of follicles from the present season and the proportion of stems that were alive at the time of sampling. Each morning at 09.00 , we checked all bushes in the two study areas for marked weevils. If no movement had occurred, the plant characteristics were noted and the distance moved recorded as zero. If the weevil had moved, the characteristics of both the source and destination bushes were noted and the distance moved was calculated from the coordinates of each bush.

\section{Nocturnal behaviour}

Preliminary observations suggested that $P$. sinaitus is nocturnal. Therefore, behavioural observations were made on two overnight sessions. We collected 17 weevils from Asclepias bushes at the study site. These were taken to the study centre, marked and placed in a large glass jar with fresh milkweed stems. We observed behaviour from 20.00 to 06.00 , using a red light so as to minimise disturbance. Every five minutes, the time and temperature were noted; then weevils were selected at random by each observer and their behaviour monitored. We recorded the number of periods of each behaviour type resting, feeding, mating, flying, fighting, grooming and walking - and the total duration (in seconds) of resting, feeding and mating. After five minutes a new set of weevils were selected and the process repeated. When a weevil flew away or fell from a stem out of the jar, it was caught and replaced.

\section{Data analysis}

We conducted multiple regressions on the number of oviposition holes (with plant size and follicle volume as independent variables), number of inner holes (with the addition of oviposition holes as an independent variable) and number of exit holes (for follicles with at least one inner hole, adding number of inner holes as a variable). All variables were entered simultaneously, and hence we report independent effects, allowing for the effects of the other variables. We analysed relationships of plant size with insect numbers and plant characteristics, and also all movement and nocturnal behaviour data, using Spearman's rank 
correlations. We used logistic regressions to investigate predictors of ant presence, and also of frass presence. Differences were analyzed with Kruskal-Wallis (test statistic $=H$ ), one-way Analysis of Variance (test statistic $=F$ ) or Mann-Whitney (test statistic $=\mathrm{U})$

\section{RESULTS}

\section{Taxonomy}

An expedition to the Sinai by two of us (M.M. and E.C.) in March 1999 allowed the collection of several adult weevils, together with pre-imaginal specimens at various stages of development. These immature individuals were bred and several more specimens hatched in the laboratory in the following weeks. The availability of these specimens allowed a comprehensive description, as well as nomenclatural and taxonomic remarks.

$P$. sinaitus was first recorded for Sinai by Peyerimhoff (1907, p. 43) as "Gen. ? (sp.). Insecte énigmatique [...], caractérisé par les yeux rapprochés sur le front, les fémurs dentés, les ongles libres et l'écusson distinct [...]. Un seul exemplaire, recuelli à l'ouady el-Ain sur un pied de Calotropis procera." [Calotropis procera (Ait.) Ait. f.]. It was many years before Pic (1930) described this species as Hylobius sinaitus Pic, 1930, based on specimens from Wadi Isla, bred from fruits of Asclepias sinaica. Dalla Torre et al. (1932) included H. sinaitus in the Coleopterorum Catalogus, but misspelled the specific epithet as Hylobius sinuatus Pic. Marshall (1952) combined $H$. sinaitus with the genus Paramecops Schönherr, 1825, again misspelled as $P$. sinuatus. This species was then cited as Hylobius sinaitus by Alfieri (1976), who gave further data on its distribution and phenology, indicating that the species was found in Wadi Isla in February and at El Kontella in March.

The genus Paramecops was named by Schönherr (1825), with Curculio farinosus Wiedemann, 1821 from Bengal as the type species. The specific epithet referred to a peculiarity of the representatives of this genus, the presence of a dense pruinose coating, apparently an exudate, covering most of the body, particularly the elytra. A further species was added, P. wiedemanni Faust, 1898 from the Kanara region of India. The genus was then included in the catalogue by Dalla Torre et al. (1932). Further taxonomic and morphological remarks were added by Aslam (1963). Morimoto (1982) described another species, P. granulatus Morimoto, 1982 from Japan.

Three genus rank names are synonyms of Paramecops. Peyerimhoff (1930) instituted the genus Asclepiadorrhynchus Peyerimhoff, 1930 for the new species Asclepiadorrhynchus solenostemmatis Peyerimhoff, 1930, based on weevils collected in the Tassili mountains of southern Sahara from another Asclepiad, Solenostemma argel Hayne. Dalla Torre et al. (1932) combined A. solenostemmatis with the genus Chitonopterus Fairmaire, 1882, a genus proposed in Fairmaire et al. (1882) for a new species from Somalia, Chitonopterus cryptorrhynchinus Fairmaire, 1882. This genus soon included two other species; C. fasciculatus Kolbe, 1883 from Guinea, and $C$. floccosus Fairmaire, 1902 from Madagascar, the latter misspelled as formosus by Sharp (1902). After the inclusion of C. solenostemmatis, Marshall (1938) described two new species, $C$. stapeliae Marshall, 1938 and $C$. stricticollis Marshall, 1938 from Southern Africa. Later, Marshall (1952, p. 267) established the synonymy between Chitonopterus and Paramecops and transferred the known species to that genus. Hustache (1956) overlooked this synonymy and included to Chitonopterus two new species from Madagascar: C. dentatus Hustache, 1956 and C. singularis Hustache 1956. Finally, Oberprieler (1988) revised the taxonomic history, composition, distribution and biology of Paramecops.

That Paramecops solenostemmatis was associated with Asclepiads, and the characters indicated in its description, led us to consider the possible identity between this species and the weevil from Sinai. One of the types of $P$. solenostemmatis was examined by one of us (E.C.), who found it not to show any significant differences from $P$. sinaitus. The study of another specimen found in the Natural History Museum in Basel (Switzerland) and examined by M.M., confirmed this opinion. The only possible difference is that the granules on the pronotum are slightly larger in the specimens from the Tassili. Thus, it is here established that Paramecops solenostemmatis (Peyerimhoff, 1930) is a synonym of Paramecops sinaitus (Pic, 1930), syn.n. The description of Paramecops solenostemmatis was published on July 18, 1930. We have been unable so far to establish the exact month of publication of Pic's description of Hylobius sinaitus, but it was published in the account of a meeting held on 29th January 1930, so it is likely that when the publication month is found, it will be before July. If the date of publication of the January meeting is found to have been after 18th July 1930, or in the unlikely event that no publication date for this work was recorded at all, Paramecops solenostemmatis (Peyerimhoff, 1930) must become the senior name for this weevil (cf. Art. 21 ICZN, 1999 for determination of date of publication). In the absence of the necessary information, we are continuing to use what we consider to be the more probable senior name, and also the more familiar to the majority of workers, Paramecops sinaitus (Pic, 1930).

Nasreddinov (1978) proposed the new genus Perihylobius Nasreddinov, 1978 for Perihylobius sogdianus Nasreddinov, 1978, a new species of Molytinae from Tajikistan. The type specimen, housed in the Zoological Institute in St. Petersburg (Russia) was examined by one of us (M.M.). Without any doubt it belongs to Paramecops as Paramecops sogdianus (Nasreddinov, 1978), comb. n.; hence, we suggest synonymy between Perihylobius and Paramecops syn. n. Paramecops sogdianus is extremely similar to $P$. farinosus, and might possibly be a synonym of this species. However, pending a complete revision of Paramecops, no further taxonomic action is undertaken here.

At the moment therefore, Paramecops comprises 12 species, some of which are very similar (E.C. and M.M., pers. obs.), distributed from Sahara to tropical Africa, Madagascar, central and south-eastern Asia and Japan. 
Biological data or knowledge of plant associations are not available for all the species; however, when known, host plants are always Asclepiads. The genus is in need of revision.

\section{Redescription of Paramecops sinaitus (Pic, 1930)}

Integument. Body and legs usually black. Antennae, and occasionally pronotum and tarsi, dark ferrugineous. Integument moderately glossy, often partially or largely covered with a consistent, moderately thickened pruinose coating, not easily removable (Fig. 1.9).

Vestiture composed of numerous hair-like setae, gold coloured, glossy, obliquely inserted in the wrinkles, curved and reclined against integument. On dorsum of rostrum setae directed centripetally or slightly towards base; pregena and lower parts with denser, longer and more raised setae, directed forwards; on sides of prothorax setae about $100 \mu \mathrm{m}$ long, slightly broadened at base, aligned, adpressed against integument and oriented upwards, on dorsum setae shorter and thinner, obliquely inserted, curved against integument and oriented forwards; on elytra setae narrow, hair-like, nearly adpressed to the body, dense but not covering integument; narrower than those on the side of the prothorax and slightly shorter; on interval 4 some longer, obliquely inserted setae form a tuft on basal third and a second tuft before declivity; on intervals 2 and 3 a tuft is present immediately beyond the second tuft of interval 4; on suture a scarcely distinct tuft is present on declivity. In several specimens the pruinose coating covers most of the elytra, mainly on the dorsum and in correspondence with the tufts of setae; legs densely hairy; ventrites with sparse longer and relatively thicker setae.

Rostrum. Rostrum nearly cylindrical, weakly broadened apically. In lateral view, dorsum nearly straight from head to basal half, then moderately and very regularly curved, almost to the apex. Surface irregularly and shallowly rough, with glossy low wrinkles but lacking distinct keels or punctures. Rare specimens possess a very narrow, irregular median line. Sides above scrobes have a narrow, shallow furrow. Apical part beyond antennal insertion smooth, more glossy and with dense, small punctures. Antennae strong (Fig. 1.5). Scape straight or barely curved forwards, moderately and regularly thickened from basal third to apex. Funicle segment one approximately 2 times longer than broad; segment 2 slightly longer than broad; segments 3 to 5 nearly subquadrate; segments 6-7 conical, broadened and transverse. Club elliptical, as long as the last five segments of the funicle. Scrobes linear, glossy, scarcely broadened basad, if at all; upper and lower margins not keeled, nearly reaching eyes at their lowermost third.

Head. Head globose. Interocular space on vertex, half as wide as the base of the rostrum. Eyes flat, elongateelliptical, closer together at the bottom and rounded at their lower margin.

Thorax. Pronotum as long as it is broad. Base strongly bisinuate, broadly curved towards elytra at middle. Maximum width at base, sides slightly convergent from base to near apex, distinctly constricted at this level and

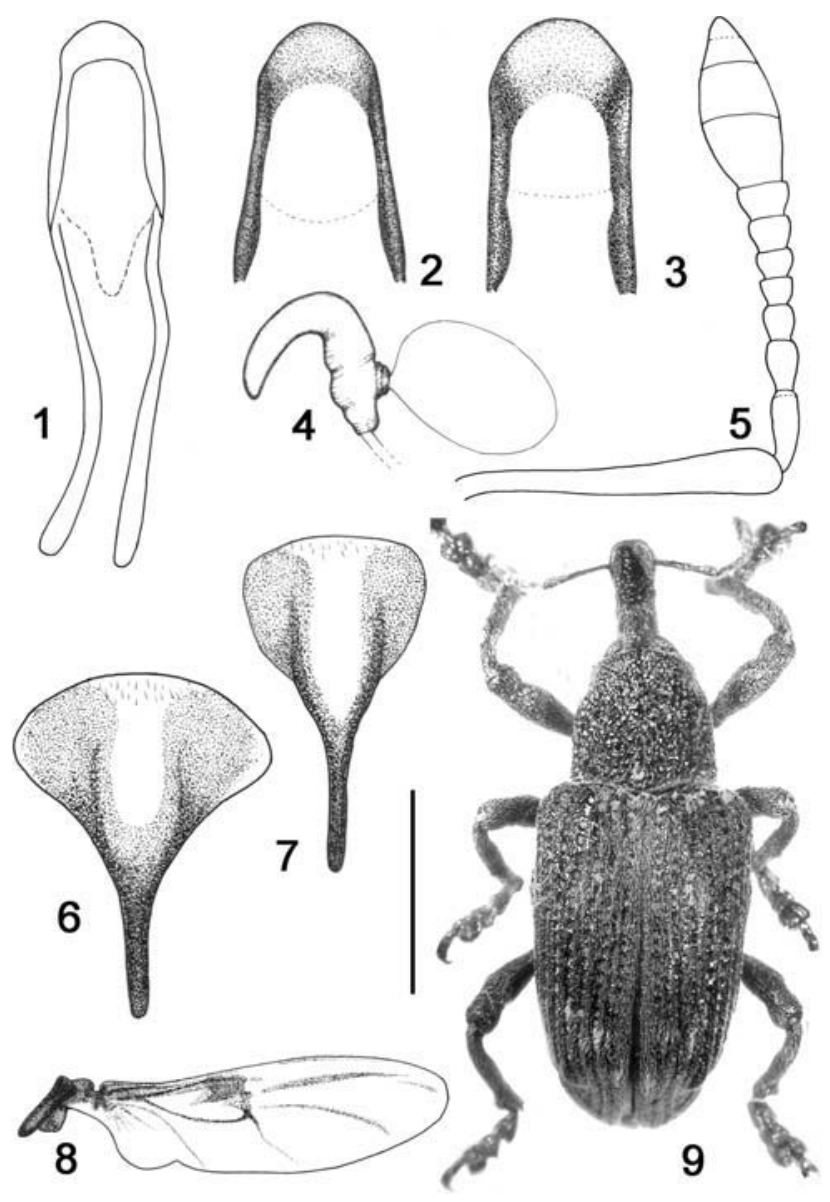

Fig. 1. Paramecops sinaitus (Pic, 1930), Egypt, Sinai, St. Katherine: aedeagus, dorsal side and detail of apex (1-2); spermatheca (4); antenna (5); sternite VIII of female (6); metathoracic wing (8); body (9). Paramecops farinosus (Wiedemann, 1821), India, Bengal, Pusa: apex of aedeagus (3); sternite VIII of female (7). Bar: $(1,5): 1 \mathrm{~mm}$; $(2-3,6-7): 0.75 \mathrm{~mm}$; (4): 0.5 $\mathrm{mm} ;(8): 8 \mathrm{~mm},(9): 16 \mathrm{~mm}$.

slightly expanded outwards at apex. Surface with dense irregular sculpture; on dorsum, rough and moderately impressed or quite shallow, with confused irregular and badly defined punctures, usually not distinct as single punctures, but as irregular depressions, delimited on their posterior margin by moderately convex interspaces, often more raised to form glossy horizontally compressed granules; sculpture on sides slightly deeper.

Elytra with maximum width at humeri, moderately broader than the base of prothorax. Sides sublinearly convergent, apex rounded with acutely but moderately prominent apex of interval 3. Subapical depression on declivity broad, triangular, well delimited between intervals 3 and 9; intervals 4 to 8 above the depression forming a large and obtuse hump. Odd and even intervals isomorphic, approximately as wide as the striae; intervals 1-5 flat or very weakly convex, smooth or wrinkled; intervals 6-10 progressively more convex, more glossy, sometimes with irregular oblong granules; striae scarcely impressed, punctures round, well delimited, seriate, approached, separated by narrow flat interspaces which 


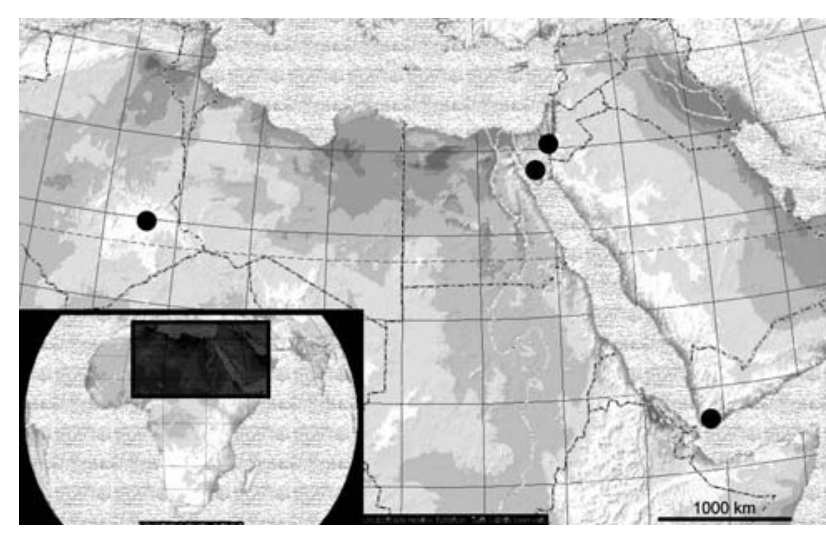

Fig. 2. Distribution of Paramecops sinaitus based on the specimens examined. Map taken from Encarta World Atlas 2000 (Microsoft Corporation), elaborated with Photoshop 7.0 (Adobe Systems Incorporated).

occasionally include a minute glossy granule. Metathoracic wings very large, macropterous (Fig. 1.8).

Legs. Fore femora scarcely broadened at middle, inner side with barely developed median teeth, hidden by the setae and the pruinose coating. Tibiae short, straight, robust, inner side indistinctly sinuate. Segment 3 of tarsi with lobes moderately developed.

Ventrites glossy, punctured; segment 1 with a large acutely triangular intercoxal projection, segment 2 slightly longer, segment 3 and 4 short, weakly convex, segment 5 shortly semicircular, transverse.

Genitalia: median lobe of aedeagus robust, sides linearly convergent, dorsum weakly sclerotized, apical lamella short and broad, regularly rounded; internal sac with minute denticles, lacking large sclerites; sternite VIII of the female with apodeme half as long as the lamina, arms scarcely extended in the lamina, sclerotisation broad, widely expanded outside of arms; spermatheca with curved but not acuminate cornu, broadened at junction with nodulus, this scarcely thickened, ramu short, conical; gonocoxites narrowly cylindrical, styli apical, cylindrical (Figs 1.1, 1.2, 1.4, 1.6).

Measurements. Length of the body without rostrum: $9.37 \mathrm{~mm}$. Rostrum: length $2.57 \mathrm{~mm}$; width at base 0.85 $\mathrm{mm}$; width at apex $0.94 \mathrm{~mm}$. Pronotum: length $2.57 \mathrm{~mm}$; width $2.71 \mathrm{~mm}$ (ratio length/width: 0.91). Elytra: length $6.68 \mathrm{~mm}$; width $4.17 \mathrm{~mm}$ (ratio length/width: 1.60). (Male specimen, St. Katherine).

Variability. The examined specimens were quite uniform for morphological traits. Limited size variation was shown $(9.00-10.05 \mathrm{~mm})$. The pruinose coating is often very dense, covering most of dorsum of elytra and completely hiding integument. There are no sexual differences, excepting the usual secondary sexual characters (ventrites 1 and 2 weakly impressed in male)

Related species. Paramecops sinaitus is very similar to the type species of the genus, $P$. farinosus, from Bengal; the latter is also associated with asclepiads, as reported on the label of a specimen housed in the British Museum in London, "on Calotropis gigantea" (Calotropis gigantea R. Br.). It mainly differs by the glossier integument, with

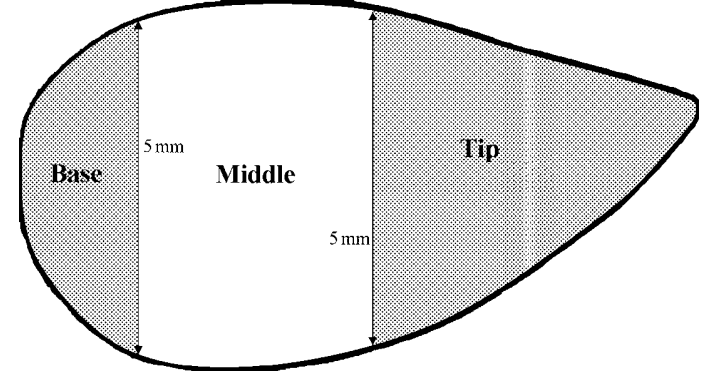

Fig. 3. Diagram of a follicle showing how the three regions were classified. The "base" was defined as the area proximal to the first point at which the diameter of the pod was $5 \mathrm{~mm}$. The "tip" was the area distal to the second point at which the diameter was $5 \mathrm{~mm}$. The remainder was the "middle".

more distinctly granulose pronotum, often having deeper and more clearly delimited punctures. The rostrum, elytra and vestiture, including the position of the tufts of setae on elytra, do not differ. Genitalia are also extremely similar, showing only small differences: The sternite 8 of female has arms more regularly sclerotised and slightly more convergent compared to P. sinaitus (Figs 1.6 and 1.7); also, the aedeagus is slightly more regularly rounded at the apex (Figs 1.2 and 1.3). The value of these limited differences for separating the two taxa at the species level cannot be evaluated based on present knowledge, especially considering that no specimens have been reported from intermediate regions, where Calotropis and other host plants are nevertheless present. For now we will identify the Sinai weevil as $P$. sinaitus, although further investigations may prove it to be a synonym of $P$. farinosus.

Distribution. We also examined specimens of $P$. sinaitus from Aden and southern Israel, this last collected on the asclepiad genus Pergularia L., housed in the British Museum in London and the Natural History Museum in Basel (Fig. 2).

\section{Plant-insect interactions}

Larger plants had more follicles (Table 1, Fig. 4) and more flower clusters $\left(\mathrm{r}_{\mathrm{s}}=0.19, \mathrm{~N}=153, \mathrm{p}=0.022\right)$. Plant size did not differ among transects $\left(\mathrm{H}_{4}=2.17, \mathrm{NS}\right)$. Weevils were more abundant on larger plants $\left(\mathrm{r}_{\mathrm{s}}=0.245, \mathrm{~N}=\right.$ $153, \mathrm{p}=0.002)$, as were aphids $\left(\mathrm{r}_{\mathrm{s}}=0.212, \mathrm{~N}=153, \mathrm{p}=\right.$ $0.009)$ and ants $\left(\mathrm{B}=0.015 \pm 0.005\right.$, $\mathrm{Wald}_{1}=8.51, \mathrm{p}=$ $0.004)$ : all were positively related to plant size. Plants with weevils on had a greater proportion of leaves eaten than plants with no weevils on (Fig. 5), and the proportion of leaves eaten increased with plant size $\left(r_{s}=0.38, N\right.$ $=153, \mathrm{p}<0.001$ ).

TABLE 1. Results of Spearman's rank correlations between plant size and the numbers of different types of follicle. $\mathrm{N}=153$ for all tests.

\begin{tabular}{lc}
\hline Follicle type & Result \\
\hline Total from previous years & $\mathrm{r}_{\mathrm{s}}=0.30, \mathrm{p}<0.001$ \\
Total from the current year & $\mathrm{r}_{\mathrm{s}}=0.31, \mathrm{p}<0.001$ \\
Total open (this year) & $\mathrm{r}_{\mathrm{s}}=0.22, \mathrm{p}=0.006$ \\
Total closed (this year) & $\mathrm{r}_{\mathrm{s}}=0.34, \mathrm{p}<0.001$ \\
\hline
\end{tabular}




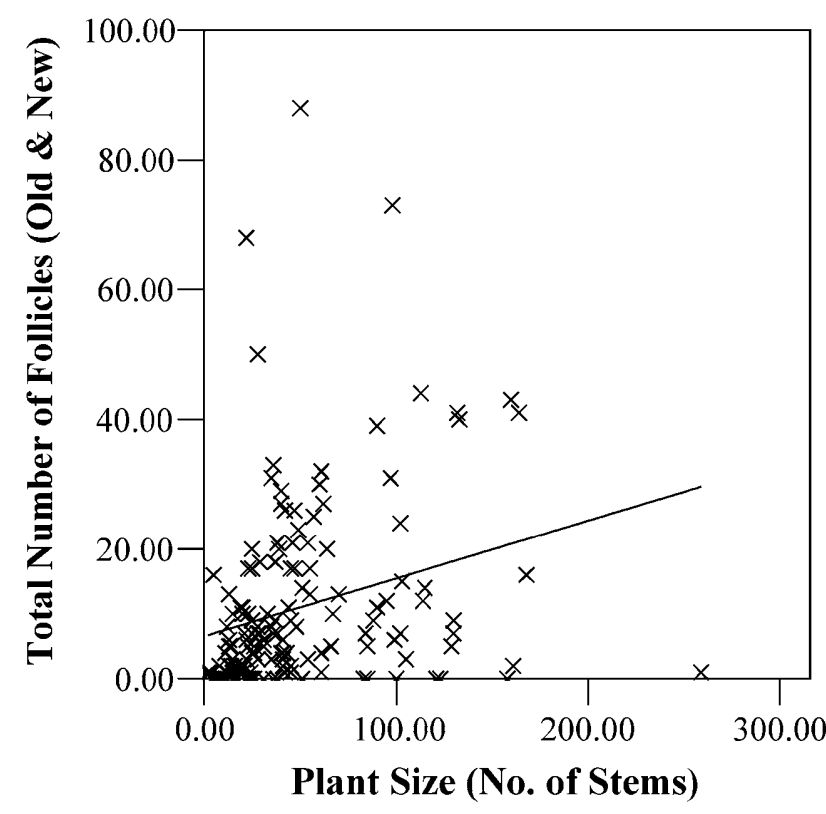

Fig. 4. Correlation between plant size, as indicated by the number of stems, and the total number of follicles of all ages $\left(\mathrm{r}_{\mathrm{s}}\right.$ $=0.42, \mathrm{~N}=153, \mathrm{p}<0.001$ ).

The follicles we examined had a total of 276 weevil oviposition holes. These were most commonly found in the middle part of the follicle, suggesting a preference for this part $\left(\chi_{1}^{2}=228, \mathrm{p}<0.001\right)$. The number of oviposition holes differed among plants $\left(\mathrm{F}_{11}=4.10, \mathrm{p}<0.001\right)$. Inspection of the residuals showed that the number of holes was Poisson-distributed, suggesting that within plants oviposition is essentially random. There were more oviposition holes on larger plants $(B=0.005 \pm 0.002, t=$ $3.14, \mathrm{p}=0.002$; Fig. 6A) and (independently) on larger follicles $(\mathrm{B}=0.053 \pm 0.016, \mathrm{t}=3.38, \mathrm{p}=0.001)$,

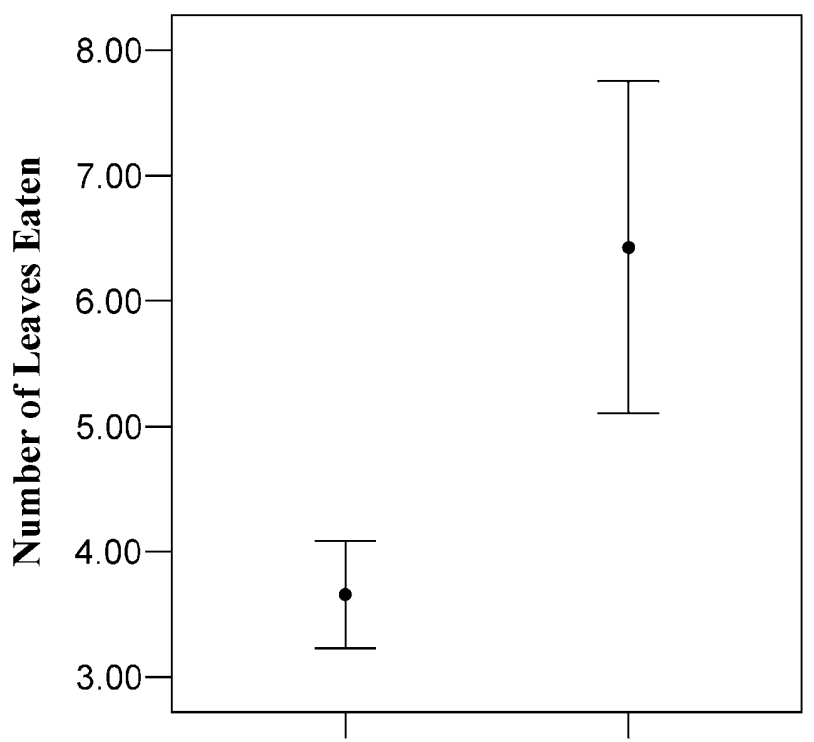

No Weevils Present Weevils Present

Fig. 5. Effect of weevil presence on the mean number of leaves eaten on one bush, from a sample of fifty $(\mathrm{U}=260.5, \mathrm{~N}$ $=152, \mathrm{p}=0.027)$.
A

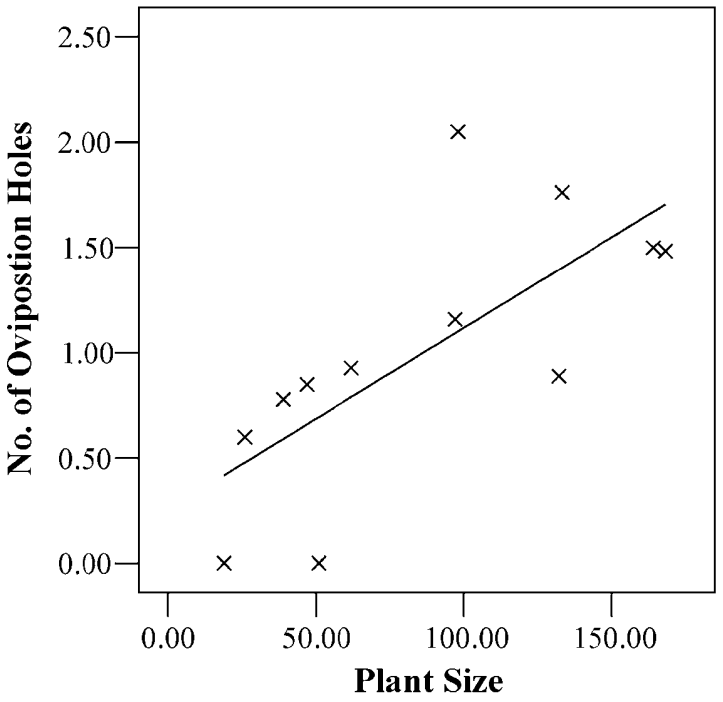

$\mathrm{B}$

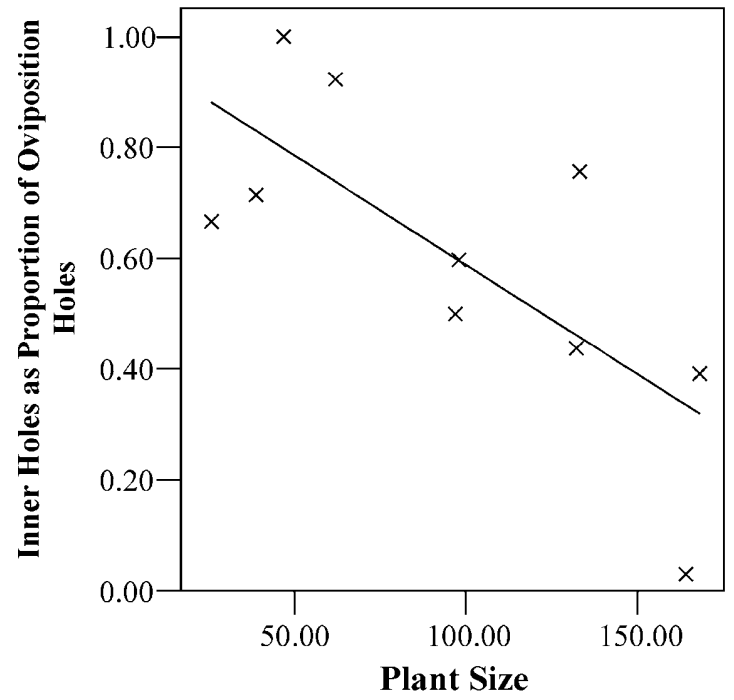

C

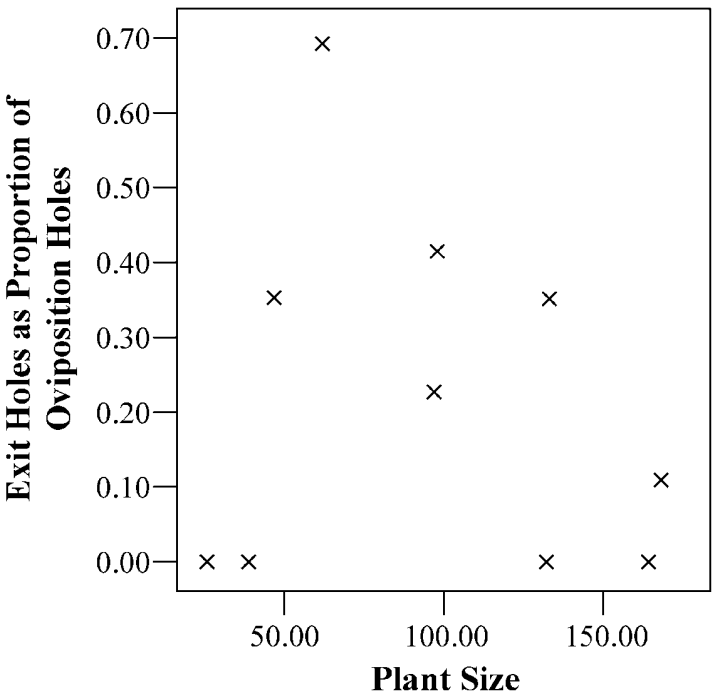

Fig. 6. Correlations between plant size and (A) mean number of oviposition holes per follicle $\left(r_{s}=0.81, N=12, p=0.001\right)$; (B) Number of holes on the inner surface of the pericarp, as a proportion of the number of oviposition holes $\left(\mathrm{r}_{\mathrm{s}}=-0.64, \mathrm{~N}=\right.$ $10, p=0.048)$; and $(\mathrm{C})$ number of exit holes as a proportion of the number of oviposition holes $\left(\mathrm{r}_{\mathrm{s}}=0.075, \mathrm{~N}=12\right.$, NS). 


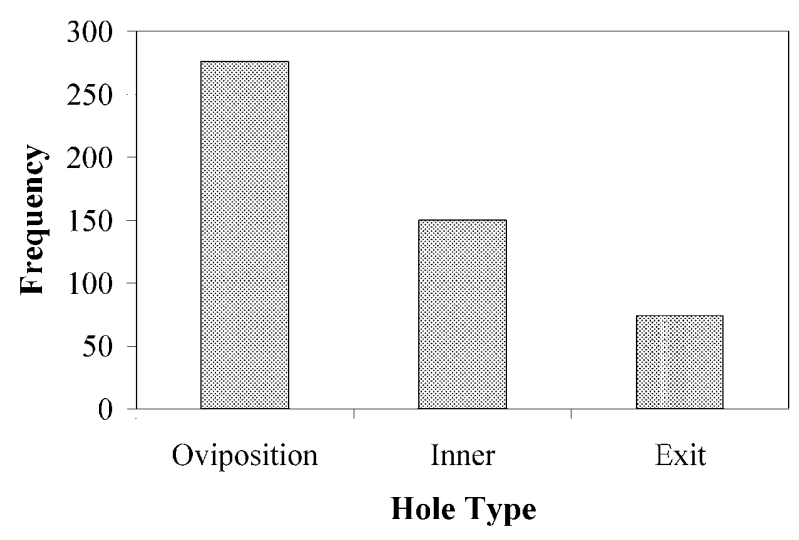

Fig. 7. Survival of weevils at each stage of development, indicated by the number of oviposition holes (total eggs laid), number of internal holes (egg survival) and number of exit holes (larval survival).

although plant size and follicle volume were not correlated $\left(r_{s}=0.063, N=12, N S\right)$ and the number of seeds in uninfested follicles did not increase with follicle volume $\left(\mathrm{r}_{\mathrm{s}}=-0.169, \mathrm{~N}=16, \mathrm{NS}\right)$.

We found a total of 150 holes on the inner surface of the follicles (Fig. 7), caused by newly-hatched larvae entering the follicle. The number of inner holes decreased with increasing plant size $(\mathrm{B}=-0.004 \pm 0.001, \mathrm{t}=-3.72$, $\mathrm{p}<0.001$; Fig. 6B) and (independently) increased with number of oviposition holes $(\mathrm{B}=0.44 \pm 0.042, \mathrm{t}=10.47$, $\mathrm{p}<0.001)$, but showed no relationship with follicle volume $(\mathrm{B}=0.008 \pm 0.01, \mathrm{t}=0.85, \mathrm{NS})$. Larval feeding was not related to follicle volume $(\mathrm{B}=0.054 \pm 0.032$, Wald $\left._{1}=2.83, \mathrm{NS}\right)$ or plant size $\left(\mathrm{r}_{\mathrm{s}}=0.26, \mathrm{~N}=12, \mathrm{NS}\right)$, although follicles in which larvae had fed were larger than those with no evidence of feeding (Mann-Whitney test: $\mathrm{U}=2188, \mathrm{~N}=208, \mathrm{p}<0.001$ ).

The 208 follicles had a total of 74 exit holes (Fig. 7); most follicles with exit holes had only one $(89 \%)$, but $8 \%$ had two, and single follicles had three and even four exit holes. The number of exit holes (on follicles with at least one inner hole) increased with the number of oviposition holes $(\mathrm{B}=0.25 \pm 0.07, \mathrm{t}=3.90, \mathrm{p}<0.001)$, possibly increased with follicle volume $(\mathrm{B}=0.02 \pm 0.01, \mathrm{t}=1.87$, $\mathrm{p}=0.065)$, but was not affected by plant size $(\mathrm{B}=-0.002$ $\pm 0.002, \mathrm{t}=-1.03$, NS; Fig. $6 \mathrm{C}$ ) or number of inner holes

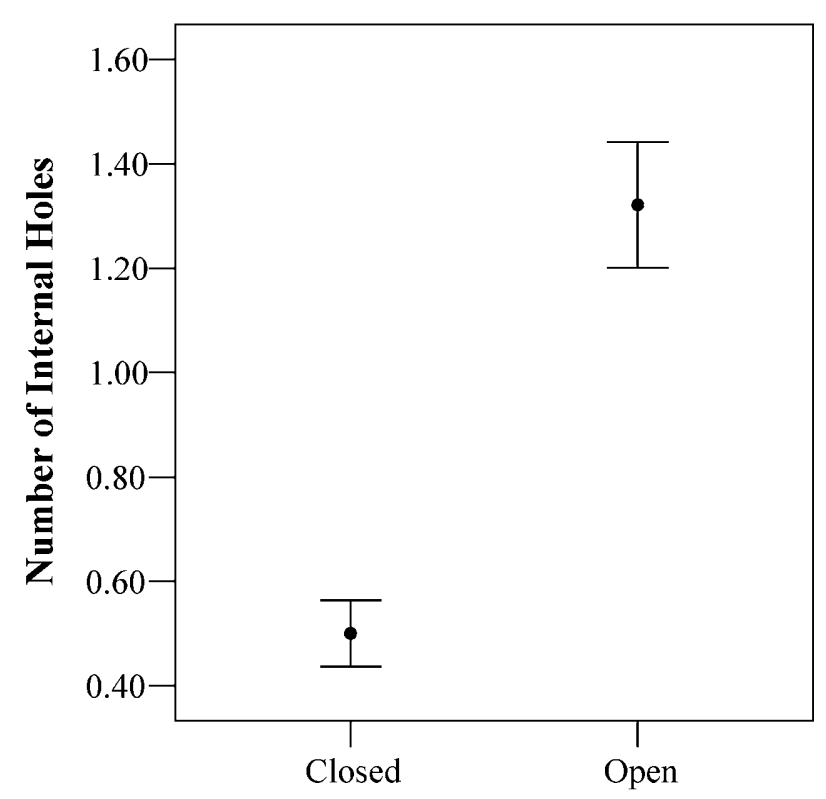

Fig. 8. Comparison of the mean number of inner holes found on closed follicles, with the number found on open follicles ( $U$ $=2030, \mathrm{~N}=208, \mathrm{p}<0.001$ ).

$(\mathrm{B}=-0.05 \pm 0.10, \mathrm{t}=-0.46, \mathrm{NS})$. The proportion of follicles that were open was positively related to the number of larvae that had entered the follicle $(\mathrm{B}=0.86 \pm 0.21$, $\mathrm{Wald}_{1}=16.50, \mathrm{p}<0.001$; Fig. 8) and the number of exit holes that had been made $\left(B=0.98 \pm 0.32\right.$, Wald $_{1}=9.43$, $\mathrm{p}=0.002)$. The proportion of follicles that were open was not significantly correlated with plant size $\left(\mathrm{r}_{\mathrm{s}}=0.36, \mathrm{~N}=\right.$ 12 , NS).

\section{Weevil movement}

Of 318 resightings of marked weevils, we observed only nine movements between bushes $(2.8 \%)$ during the course of the study. The distance moved was unrelated to bush height $\left(\mathrm{r}_{\mathrm{s}}=0.003, \mathrm{~N}=318, \mathrm{NS}\right)$, bush width $\left(\mathrm{r}_{\mathrm{s}}=\right.$ $0.083, \mathrm{~N}=318$, NS), bush length $\left(\mathrm{r}_{\mathrm{s}}=0.004, \mathrm{~N}=318\right.$, NS), number of follicles from the current year (data insufficient), number of old follicles $\left(\mathrm{r}_{\mathrm{s}}=-0.051, \mathrm{~N}=318\right.$, $\mathrm{NS})$ and the percentage of stems that were alive $\left(\mathrm{r}_{\mathrm{s}}=\right.$ $0.014, \mathrm{~N}=318, \mathrm{NS})$.

TABLE 2. Correlations between time and temperature, and a number of variables relating to nocturnal behaviour.

\begin{tabular}{lcc}
\hline Variable & Time & Temperature \\
\hline Resting frequency & $\mathrm{r}_{\mathrm{s}}=0.042, \mathrm{NS}$ & $\mathrm{r}_{\mathrm{s}}=0.013, \mathrm{NS}$ \\
Resting duration & $\mathrm{r}_{\mathrm{s}}=-0.075, \mathrm{NS}$ & $\mathrm{r}_{\mathrm{s}}=0.13, \mathrm{p}=0.011$ \\
Feeding frequency & $\mathrm{r}_{\mathrm{s}}=0.14, \mathrm{p}=0.003$ & $\mathrm{r}_{\mathrm{s}}=-0.15, \mathrm{p}=0.002$ \\
Feeding duration & $\mathrm{r}_{\mathrm{s}}=0.14, \mathrm{p}=0.003$ & $\mathrm{r}_{\mathrm{s}}=-0.15, \mathrm{p}=0.002$ \\
Mating frequency & $\mathrm{r}_{\mathrm{s}}=-0.14, \mathrm{p}=0.004$ & $\mathrm{r}_{\mathrm{s}}=0.058, \mathrm{NS}$ \\
Mating duration & $\mathrm{r}_{\mathrm{s}}=-0.14, \mathrm{p}=0.004$ & $\mathrm{r}_{\mathrm{s}}=0.058, \mathrm{NS}$ \\
Flying frequency & $\mathrm{r}_{\mathrm{s}}=0.005, \mathrm{NS}$ & $\mathrm{r}_{\mathrm{s}}=-0.009, \mathrm{NS}$ \\
Walking frequency & $\mathrm{r}_{\mathrm{s}}=0.076, \mathrm{NS}$ & $\mathrm{r}_{\mathrm{s}}=-0.099, \mathrm{p}=0.045$ \\
Grooming frequency & $\mathrm{r}_{\mathrm{s}}=-0.005, \mathrm{NS}$ & $\mathrm{r}_{\mathrm{s}}=-0.034, \mathrm{NS}$ \\
Fight frequency & Insufficient data & Insufficient data \\
\hline
\end{tabular}




\section{Nocturnal behaviour}

Results from the nocturnal behaviour observations are displayed in Table 2 . The duration of periods of inactivity increased with temperature. The frequency of these periods was not related to either time or temperature. Periods of feeding became longer and more frequent as the night progressed, and as temperature decreased. Mating behaviour decreased in duration and frequency with time but was not related to temperature. Walking behaviour became less frequent with increasing temperature but showed no relationship with time. Neither flying nor grooming was associated with either time or temperature and we observed too few fights to analyse this behaviour.

\section{DISCUSSION}

Fruits and seeds generally contain high levels of nutrients (Morris, 1991), and chemical analysis of A.sinaica has shown that its seeds contain the lowest concentration of cardenolides (El-Askary et al., 1995b). Thus the larvae feed on the best quality, least toxic food, and the main problem for the hatchling is to reach it through the highly toxic pericarp. The female weevil does not have a long ovipositor with which to place her egg right within the follicle itself, and therefore she does not spatially avoid the chemical defences. In a similar interaction in the USA between Rhyssomatus lineaticollis and A. syriaca, the female lays a first brood of eggs in the stem and a second in the follicles, but by doing so she also does not spatially avoid chemical defences (Fordyce \& Malcolm, 2000). There was no evidence of any oviposition in the stem of Asclepias sinaica (C. Hancock, pers. obs.).

Most oviposition holes were in the middle section of the seed follicle. The reason for this is not certain but may be because the pericarp is thinner in this area. The positive correlation between follicle volume and number of oviposition holes suggests that female weevils selectively oviposit on larger follicles. Although the number of seeds was not correlated with follicle volume, there may be a positive relationship between follicle size and seed size (pers. obs.), and therefore larger follicles may contain more food for developing larvae. Other species of weevil are known to avoid ovipositing on follicles that have already been visited, to avoid competition among larvae (Roitberg \& Prokopy, 1987). However in this study, the number of holes per follicle followed a Poisson distribution, suggesting that the choice of follicle was unaffected by whether it already contained eggs.

Perhaps not surprisingly, the level of resources in the follicle (as indexed by follicle volume) had no effect on the number of larvae successfully penetrating, and was also not a predictor of the occurrence of larval feeding. On the other hand, it was surprising that the number of exit holes showed only a marginally significant relationship with follicle volume, but perhaps we had too few instances of multiple exit holes to demonstrate the relationship clearly. After the larvae have entered the follicle, it seems likely that intraspecific competition for food would affect the proportion that survives to emerge as adults.

The size of the milkweed plant had a negative effect on successful penetration of larvae into the follicle. This may be the result of systematic differences in plant chemistry among plants of different sizes, presumably implying greater defences in larger plants. The follicular pericarp contains high concentrations of cardenolides (El-Askary et al., 1995b), and therefore exposure to plant defensive chemicals is greatest at the egg stage of development. One might predict a tradeoff between growth and defence (Zangerl \& Berenbaum, 2005), but this may not be obvious because where there are large differences in resource budgets among individual plants, positive instead of negative correlations are often seen (van Noordwijk \& de Jong, 1986). Larger plants generate more resources via photosynthesis, and hence may be able to produce relatively more secondary metabolites, allowing better protection against herbivory. The higher number of herbivores and the greater proportion of leaves eaten on larger plants seem to contradict this suggestion, although herbivores that specialize on milkweed may be able to detoxify cardenolides. An analysis of individual differences in plant chemistry is needed to resolve this issue. Whatever causes the reduction in survival, it raises the question of why females show a tendency to oviposit on larger plants. These plants may be preferred because they have a higher number of young leaves, which may contain a lower concentration of cardenolides. Given the relatively sedentary behaviour of Paramecops sinaitus, oviposition choice may have an important effect on postemergence survival.

Our results suggest that each day, only three weevils in every 100 will move among hostplants, and no weevil moved more than $12 \mathrm{~m}$ during the study. This is a very low rate of movement, although not uncommonly recorded in host-specialised insects (e.g. butterflies: Thomas \& Hanski, 1997). In $R$. lineaticollis, another monophagous weevil feeding on Asclepias, 38-51\% of moves were non-zero, and one moved $680 \mathrm{~m}$ (St Pierre \& Hendrix, 2003), clearly a much higher frequency of movement. Thus Paramecops sinaitus is extremely sedentary in its behaviour. The distance that weevils travelled was not correlated with any of the measured characteristics of the milkweed plant. Movements may have been determined by competition with other herbivores for food. In this case we may expect weevil movements to be related to the number of herbivores in the source bush, but further work will be needed to address this hypothesis.

Many weevils are nocturnal (pers. obs.), and Paramecops sinaitus is no exception; in the Sinai mountain environment this is probably to avoid desiccation in the heat of the day. There seem to be two peaks in activity, just after sunset and shortly before sunrise. From our data mating behaviour is confined to the first peak, whereas feeding and other activities are undertaken more frequently in the later hours of the night. Much more effort needs to be put into recording the reproductive behaviour 
of this weevil before we can characterise it accurately, but it is very suitable for such studies because once marked, its sedentary habits and host specificity will make individuals easy to watch and record over long periods.

It is clear that Asclepias sinaica and Paramecops sinaitus are involved in a tight interaction. It is usually assumed that coevolutionary interactions require reciprocal effects on fitness, although detailed examples where such reciprocal effects have been demonstrated are rare (one is the parsnip webworm Depressaria Haworth on the parsnip Pastinaca Linnaeus: Zangerl \& Berenbaum, 1997). We have shown that female oviposition choices among individual plants affect larval performance, suggesting a negative influence of the cardenolides on weevil fitness. P. sinaitus appears to have evolved "latex-canal sabotage behaviour", a behavioural mechanism to overcome asclepiad defences, allowing the adults to feed on the leaves. A very similar behaviour is shown by Rhyssomatus lineaticollis (Agrawal \& Malcolm, 2002) and other milkweed insects (Zalucki et al., 2001), and the convergent evolution of biochemical, physiological, ecological and behavioural traits in milkweed-feeding weevils might be an interesting avenue for further study.

Some herbivorous insects sequester plant secondary metabolites to use in their own defence against predators; for example the monarch butterfly Danaus plexippus uses milkweed cardenolides (Martin et al., 1992). Most of these species are aposematically coloured. It would be interesting to investigate the function of the pruinose coating of $P$. sinaitus, whether it is cryptic or aposematic and if it is derived from the milkweed cardenolides.

It remains to be seen how much of an effect $P$. sinaitus has on host fitness. Plants with adult weevils had a greater proportion of leaves eaten than those without, but this may not necessarily affect plant survival or reproduction. Larval weevils almost certainly reduce plant fitness because a single larva eats all of the seeds in a follicle. Just how significant this is in plant population dynamics remains to be seen.

Plants are often host to a number of different herbivorous insects which may exert complex selective pressures on each other, resulting in "diffuse" or "guild" coevolution (Fox, 1988). A. sinaica is no exception with four species being recorded in this study. Further study will be necessary to determine if, and how, these different species interact. Where known the host plants of Paramecops are always Asclepiads, consistent with Ehrlich \& Raven's (1964) escape-and-radiation hypothesis. Phylogenetic studies of these taxa may reveal how closely, and for how long they have coevolved.

ACKNOWLEDGEMENTS. We thank the following: the Connecting Futures programme of the British Council (Egypt) for funding the participation of Egyptian undergraduates; the British Council LINK scheme for other financial support; the staff of the Environmental Research Centre, Suez Canal University for logistical support. We are extremely grateful for the time and effort of P. Stueben (Curculio Institute, Mönchengladbach), L. Behne (German Entomological Institute, Eberswald) and R. Thompson (Natural History Museum, UK) in identifying the weevil in the early stages of this work. D. Shuker made valuable suggestions on an earlier draft.

\section{REFERENCES}

AbDel-Azim N.S. 1998: A cardenolide glycoside from Gomphocarpus sinaicus. Phytochemistry 49: 273-275.

Agrawal A.A. \& Malcolm S. 2002: Once upon a milkweed. Nat. Hist. 111: 48-53.

Agrawal A.A. \& Van Zandt P.A. 2003: Ecological play in the coevolutionary theatre: genetic and environmental determinants of attack by a specialist weevil on milkweed. J. Ecol. 91: 1049-1059.

Alfieri A. 1976: The Coleoptera of Egypt. Mém. Soc. Entomol. Egypte 5: 1-361.

Aslam N.A. 1963: On the genera of Indo-Pakistan Cleoninae and Hylobiinae (Coleoptera: Curculionidae). Bull. Br. Mus. Nat. Hist. (Entomol.) 13: 47-66.

Becerra J.X., Venable D.L., Evans P.H. \& Bowers W.S. 2001: Interactions between chemical and mechanical defenses in the plant genus Bursera and their implications for herbivores. $\mathrm{Am}$. Zool. 41: 865-876.

Bernays E. \& Graham M. 1988: On the evolution of host specificity in phytophagous arthropods. Ecology 69: 886-892.

Boulos L. 2000: Flora of Egypt. Vol. 2 (Geraniaceae - Boraginaceae). Al Hadara Publishing, Cairo, 352 pp.

Chown S.L. \& Nicholson S.W. 2004: Insect Physiological Ecology. Oxford University Press, Oxford, 254 pp.

Collentette S. 1985: An Illustrated Guide to the Flowers of Saudi Arabia. Scorpion Publishing, London, 514 pp.

Dalla Torre K.W., Schenkling S. \& Marshall G.A.K. 1932: Curculionidae: Hylobiinae. In Junk W. \& Schenkling S. (eds): Coleopterorum Catalogus. Pars 122. Junk, Berlin, 112 pp.

Ehrlich P.R. \& Raven P.H. 1964: Butterflies and plants: A study in coevolution. Evolution 18: 586-608.

El-Askary H., Hölzl J., Hilal S. \& El-Kashoury E. 1993: Cardenolide glycosides with doubly linked sugars from Gomphocarpus sinaicus. Phytochemistry 34: 1399-1402.

El-Askary H., Hölzl J., Hilal S. \& El-Kashoury E. 1995a: Cardenolide glycosides from Gomphocarpus sinaicus. Phytochemistry 38: 943-946.

El-Askary H., Hölzl J., Hilal S. \& El-Kashoury E. 1995b: A comparative study of the cardenolide content of different organs of Gomphocarpus sinaicus. Phytochemistry 38: $1181-1184$

El-Banna S., Zalat S., Khambay B., Mellor I., Duce I.R. \& GiLbert F. 2003: Nicotinic acetylcholine receptor ligands from the Egyptian milkweed, Asclepias sinaica. Comp. Biochem. Physiol. (A) 134: S72.

Fairmaire L., Landsberge V. \& Bourgeois J. 1882: Mission G. Révoil aux Pays Çomalis. Faune et Flore. Coléoptères Recuéllis par M.G. Révoil chez les Çomalis. J. Tremblay, Paris, 104 pp.

Farrell B.D. \& Mitter C. 1990: Phylogenesis of insect plant interactions - have Phyllobrotica leaf beetles (Chrysomelidae) and the Lamiales diversified in parallel? Evolution 44: 1389-1403.

FARrell B.D., Dussourd D.E. \& MitTER C. 1991: Escalation of plant defense - do latex and resin canals spur plant diversification. Am. Nat. 138: 881-900.

FordyCE J.A. \& MALCoLm S.B. 2000: Specialist weevil, Rhyssomatus lineaticollis, does not spatially avoid cardenolide defenses of common milkweed by ovipositing into pith tissue. J. Chem. Ecol. 26: 2857-2874.

Fox L.R. 1988: Diffuse coevolution within complex communities. Ecology 69: 906-907. 
FraENKel G.S. 1959: Raison d'être of secondary plant substances. Science 129: 1466-1470.

FutuYMA D.J. \& Gould F. 1979: Associations of plants and insects in deciduous forest. Ecol. Monogr. 49: 33-50.

Hustache A. 1956: Synopsis des Curculionides de Madagascar. Troisième supplèment. Bull. Acad. Malgache (N.S.) 33: 65-210.

InTERnational Commission on Zoological Nomenclature 1999: ICZN. 4th ed., Adopted by the International Union of Biological Sciences. The International Trust for Zoological Nomenclature, London.

Mabberley D.J. 1997: The Plant Book: A Portable Dictionary of the Vascular Plants. Cambridge University Press, Cambridge, $874 \mathrm{pp}$.

Malcolm S.B. 1991: Cardenolide-mediated interactions between plants and herbivores. In Rosenthal G.A. \& Berenbaum M.R. (eds): Herbivores: Their Interactions with Secondary Plant Metabolites. Vol. 1: The Chemical Participants. Academic Press, San Diego, pp. 251-296.

Marshall G.A.K. 1938: New Curculionidae (Col.) from Southern Africa. Ann. Mag. Nat. Hist. 11: 178-195.

Marshall G.A.K. 1952: Taxonomic notes on Curculionidae. Ann. Mag. Nat. Hist. 12: 261-270.

Martin R.A., Lynch S.P., Brower L.P., Malcolm S.B. \& Van Hook T. 1992: Cardenolide content, emetic potency, and thinlayer chromatography profiles of Monarch Butterflies, Danaus plexippus, and their larval host-plant milkweed, Asclepias humistrata, in Central Florida. Chemoecology 3: $1-13$.

Moriмото K. 1982: The family Curculionidae of Japan. 1. Subfamily Hylobiinae. Esakia 19: 51-121.

Morris M.G. 1991: Weevils. Naturalists Handbooks 16. Richmond, Slough, $76 \mathrm{pp}$.

NASREdDinov Kh.A. 1978: Novyi rod zhukov-dolgonosikov (Coleoptera, Curculionidae) is Tadzhikistana. Izv. Akad. Nauk Tadzhik. SSR. (Biol.) 3: 109-110.

van NoORdWIJK A.J. \& DE JoNG G. 1986: Acquisition and allocation of resources: their influence on variation in life history tactics. Am. Nat. 128: 137-142.

OBERPRIELER R.G. 1988: The life history of Paramecops stapeliae (Marshall) with a review of the genus Paramecops (Coleoptera: Curculionidae: Molytinae). J. Nat. Hist. 22: $1451-1464$.
Peyerimhoff P. de 1907: Liste de Coléoptères du Sinai. L'Abeille, Mém. Entomol. 31: 1-49.

Peyerimhoff P. DE 1930: Nouveaux Coléoptères du NordAfricain. Soixante-troisième note. Récoltes de M.C. Dumont en Tunisie méridionale. Bull. Soc. Entomol. Fr. 12: 202-207.

PIC M. 1930: Deux nouveaux Coléoptères d'Egypte et Sinai. Bull. Soc. R. Entomol. Egypte 14: 1-2.

RoItberg B.D. \& Prokopy R.J. 1987: Insects that mark host plants. Bioscience 37: 400-406.

Sabelis M.W., Van BaAlen M., Bakker F.M., Bruin J., Drukker B., Egas M., Janssen A.R.M., Lesna I.K., Pels B., VAN RiJn P.C.J. \& Scutareanu P. 1998: The evolution of direct and indirect plant defence against herbivorous arthropods. In Olff H., Brown V.K. \& Drent R.H. (eds): Herbivores: Between Plants and Predators. Blackwell Science, Oxford, pp. 109-168.

SCHÖNHERR C.J. 1825: Continuatio tabulae synopticae familiae Curculionidum. Isis von Oken 5: columns 581-588.

SHARP D. 1902: Insecta. In Sharp D. (ed.): The Zoological Record Volume the Thirty-Eighth. Being Records of Zoological Literature Relating Chiefly to the Year 1901. Zoological Society, London, $309 \mathrm{pp}$.

St. Pierre M. \& Hendrix S.D. 2003: Movement patterns of Rhyssomatus lineaticollis Say (Coleoptera: Curculionidae) within and among Asclepias syriaca (Asclepiadaceae) patches in fragmented landscapes. Ecol. Entomol. 28: 579-586.

Thomas C.D. \& HANSKI I. 1997: Butterfly metapopulations. In Hanski I. \& Gilpin M.E. (eds): Metapopulation Biology: Ecology, Genetics and Evolution. Academic Press, San Diego, pp. 359-386.

Zalucki M.P., Malcolm S.B., Paine T.D., Hanlon C.C., Brower L.P. \& Clarke A.R. 2001: It's the first bites that count: survival of first-instar monarchs on milkweeds. Austr. Ecol. 26: 547-555.

Zangerl A.R. \& Berenbaum M.R. 1997: Cost of chemically defending seeds: furanocoumarins and Pastinaca sativa. Am. Nat. 150: 491-504.

ZANGerL A.R. \& BERENBAUM M.R. 2005: Increase in toxicity of an invasive weed after reassociation with its coevolved herbivore. Proc. Nat. Acad. Sci. 102: 15529-15532.

Received September 19, 2006; revised and accepted February 5, 2007 